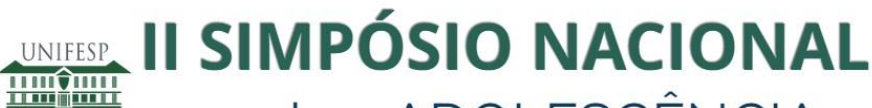 sobre ADOLESCÊNCIA: Vulnerabilidades, Protagonismos e Desafios
}

\section{Construindo uma cultura de prevenção: discussões sobre o consumo de bebida alcoólica na adolescência}

\author{
Paula Aparecida Borges de Oliveira \\ E-mail: paula.borgespcnp@gmail.com \\ Kátia Martins Rodrigues \\ Diretoria de Ensino Leste 3
}

\begin{abstract}
Como citar:
OLIVEIRA, Paula Aparecida Borges de; RODRIGUES, Kátia Martins. Construindo uma cultura de prevenção: discussões sobre o consumo de bebida alcoólica na adolescência. In: II SIMPÓSIO NACIONAL SOBRE ADOLESCÊNCIA: VULNERABILIDADE, PROTAGONISMOS E DESAFIOS, 2. 2016, São Paulo. Anais...[S.I]: 2016. p. 62-63.

DOI: http://dx.doi.org/10.22388/2525-5894.2016.042
\end{abstract}

Estudos demonstram que ao longo dos anos, tem sido crescente o aumento do consumo de bebida alcoólica por adolescentes. Seus efeitos e consequências sejam eles biológicos, sociais ou culturais tem suscitado a sociedade a se debruçar em pesquisas e discussões sobre o impacto deste consumo no cotidiano da população mundial. Neste sentido, o objetivo deste trabalho é contribuir para implementação da cultura de prevenção nas escolas com vistas a incentivar a construção de ações e projetos contínuos, voltados para a discussão do consumo de bebida alcoólica na adolescência. Para isso, em 2014, foram realizados encontros formativos com professores (as) da Diretoria de Ensino Leste 3 voltados para discussões sobre o Consumo de Álcool e outras Drogas. Em 2015, os encontros formativos continuaram com foco especificamente, para reflexões sobre o consumo de bebida alcoólica na adolescência. Foi articulado com os docentes, uma pesquisa amostral nas escolas da Diretoria de Ensino Leste 3 para identificar o que os(as) alunos(as) pensam e vivenciam em relação à bebida alcoólica e, em 2016, as discussões nos encontros formativos foram ampliadas para vulnerabilidades que podem estar relacionadas ao consumo de bebida alcoólica, e foram estabelecidas parcerias entre outros membros da Diretoria de Ensino responsáveis por outras pastas como: Grêmio Estudantil, Programa Escola da Família e o Sistema de Proteção Escolar, além de parcerias externas, como o CRAS/CREAS e Instituições voltadas a estudos sobre vulnerabilidades e palestrantes especialistas na área de saúde e prevenção. Os resultados obtidos durante a realização deste projeto foram: em 2014, foi realizado 3 encontros formativos para docentes voltados para sensibilizar sobre a importância de conhecer e trabalhar nas escolas com a estratégia de redução de danos; em 2015, foi realizada uma pesquisa amostral em 52 escolas dos Anos Finais e Ensino Médio e identificamos que $64 \%$ dos estudantes participantes da pesquisa, consumiram algum tipo de bebida alcoólica; a partir dos resultados da pesquisa, foram realizados encontros formativos com docentes para 
discutirmos possíveis intervenções com vistas à prevenção com foco na estratégia de redução de danos e após estas discussões, foi realizada a I Mostra de Intervenções Culturais- Reflexões sobre o Consumo de Bebida Alcoólica na Fábrica de Cultura da Cidade Tiradentes com a participação de aproximadamente 180 pessoas (alunos (as), gestores (as), professores (as) e representantes da comunidade); e, em 2016, o trabalho abrangeu 77 escolas jurisdicionadas pela Diretoria de Ensino, envolvendo mais de 200 pessoas de todos os segmentos de ensino (Anos Iniciais, Finais e Ensino Médio) e firmou-se parcerias com os responsáveis pelas pastas/programas: Grêmio Estudantil, Sistema de Proteção Escolar e Programa Escola da Família. Além disso, iniciou-se a construção de uma rede colaborativa, envolvendo representantes de instituições voltadas para estudos e intervenções sobre vulnerabilidades e palestrantes especialistas na área de saúde e prevenção. Podemos constatar por meio de registros enviados pelas escolas à Diretoria de Ensino, relatos dos participantes envolvidos no projeto e acompanhamentos que realizamos nas unidades escolares, que houve uma grande mobilização das escolas no desenvolvimento de ações e projetos direcionados ao consumo de álcool, outras drogas e diferentes vulnerabilidades sociais que não estão necessariamente relacionadas ao consumo de álcool. Portanto, as escolas têm apresentado preocupações e intervenções voltadas para estas vulnerabilidades durante o período de realização deste projeto.

Palavras-Chaves: Adolescência. Bebida alcoólica. Prevenção. 